\title{
Predictive value of neuron-specific enolase for prognosis in patients with moderate or severe traumatic brain injury: a systematic review and meta-analysis
}

\author{
Eric Mercier MD MSc, Amélie Boutin MSc, Michèle Shemilt MSc, François Lauzier MD MSc, \\ Ryan Zarychanski MD MSc, Dean A. Fergusson PhD, Lynne Moore PhD, Lauralyn A. McIntyre MD MSc, \\ Patrick Archambault MD MSc, France Légaré MD PhD, François Rousseau MD MSc, \\ François Lamontagne MD MSc, Linda Nadeau MD, Alexis F. Turgeon MD MSc
}

Abstract

Background: Prognosis is difficult to establish early after moderate or severe traumatic brain injury despite representing an important concern for patients, families and medical teams. Biomarkers, such as neuron-specific enolase, have been proposed as potential early prognostic indicators. Our objective was to determine the association between neuron-specific enolase and clinical outcomes, and the prognostic value of neuron-specific enolase after a moderate or severe traumatic brain injury.

Methods: We searched MEDLINE, Embase, The Cochrane Library and Biosis Previews, and reviewed reference lists of eligible articles to identify studies. We included cohort studies and randomized controlled trials that evaluated the prognostic value of neuronspecific enolase to predict mortality or Glasgow Outcome Scale score in patients with moderate or severe traumatic brain injury. Two reviewers independently collected data. The pooled mean differences were analyzed using random-effects models. We assessed risk of bias using a customized Quality Assessment of Diagnostic Accuracy Studies (QUADAS-2) tool. Subgroup and sensitivity analyses were performed based on a priori hypotheses.

Results: We screened 5026 citations from which 30 studies (involving 1321 participants) met our eligibility criteria. We found a significant positive association between neuron-specific enolase serum levels and mortality (10 studies, $n=474$; mean difference [MD] 18.46 $\mu \mathrm{g} / \mathrm{L}$, 95\% confidence interval [Cl] 10.81 to $26.11 \mu \mathrm{g} / \mathrm{L} ; I^{2}=83 \%$ ) and a Glasgow Outcome Scale $\leq 3$ (14 studies, $n=603 ; \mathrm{MD} 17.25 \mu \mathrm{g} / \mathrm{L}, 95 \%$ $\mathrm{Cl} 11.42$ to $\left.23.07 \mu \mathrm{g} / \mathrm{L} ; I^{2}=82 \%\right)$. We were unable to determine a clinical threshold value using the available patient data.

Interpretation: In patients with moderate or severe traumatic brain injury, increased neuron-specific enolase serum levels are associated with unfavourable outcomes. The optimal neuron-specific enolase threshold value to predict unfavourable prognosis remains unknown and clinical decision-making is currently not recommended until additional studies are made available.

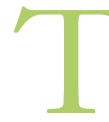

raumatic brain injury is the leading cause of death and disability in young adults. ${ }^{1,2}$ An important proportion of patients with severe traumatic brain injury will have a long-term or lifelong-related disability of physical, cognitive or behavioural origin., Quality of life of both the patient and his or her family can be substantially impaired. ${ }^{5}$ Therefore, early determination of prognosis is crucial for patients and clinicians. ${ }^{6}$ However, despite the availability of clinical, radiologic and electrophysiologic indicators associated with prognosis after traumatic brain injury, ${ }^{7-9}$ current prognostic indicators and models are of limited utility. ${ }^{10,11}$

Most deaths following traumatic brain injury will occur after a decision to withdraw life-sustaining therapies. These decisions are known to be variable across centres, and the process through which they are taken is not well understood., ${ }^{5,12} \mathrm{~A}$ broader multimodal scope is essential to better understand and accurately predict short-, mid- and long-term outcomes in patients with moderate and severe traumatic brain injury and assist with decision-making in the context of withdrawal of life-sustaining therapies.

The identification of tissue biomarkers as prognostic markers in patients with severe traumatic brain injury is of clinical interest ${ }^{11-14}$ and has been identified as a research priority. ${ }^{15}$ Neuron-specific enolase, an isoenzyme of the glycolytic enzyme enolase found in central and peripheral neurons, ${ }^{16}$ is

Competing interests: See end of article.

This article has been peer reviewed.

Correspondence to: Alexis Turgeon, alexis.turgeon@fmed.ulaval.ca CMAJ Open 2016. DOI:10.9778/cmajo.20150061 
one of the most studied biomarkers. ${ }^{14}$ It has been suggested as a neurologic prognostic indicator following cardiac arrest; ${ }^{17}$ however, its association with short-, mid- and long-term prognosis is unclear in patients with traumatic brain injury and is not part of standard practice. ${ }^{14} \mathrm{~A}$ recent systematic review on the topic did not identify several published studies and used a suboptimal methodology to pool data. ${ }^{18}$ Therefore, we performed a systematic review and a meta-analysis of prognostic studies to evaluate the association between neuronspecific enolase and clinical outcomes, and its prognostic value after moderate or severe traumatic brain injury.

\section{Materials and methods}

We developed a protocol according to the guidance provided by the Cochrane Collaboration recommendations, ${ }^{19}$ and we reported results according to the Preferred Reporting Items for Systematic Reviews and Meta-Analyses (PRISMA) statement. ${ }^{20}$

\section{Search strategy}

We conducted a literature search using MEDLINE, Embase, The Cochrane Library and Biosis Previews (from their inception to November 2015). We used validated combinations of terms for prognostic studies providing optimal sensitivity for both MEDLINE and Embase. ${ }^{21,22}$ To maximize sensitivity, we used broad text and medical subject headings (MeSH) or Emtree terms for traumatic brain injury and biomarkers. No language restrictions were applied. Studies in languages other than English were translated as required. The full search strategy for MEDLINE is in Appendix 1 (available at www. cmajopen.ca/content/4/3/E371/suppl/DC1). Search strategies used for the other databases were adapted from our MEDLINE search strategy. We reviewed reference lists from included articles, pertinent previous narrative and systematic reviews, and we searched conference proceedings from relevant meetings (Appendix 2, available at www.cmajopen.ca/ content/4/3/E371/suppl/DC1).

\section{Study selection}

Citations from the literature searches were combined, and duplicates were excluded using EndNote version X6 (Thomson Reuters). Pairs of reviewers (E.M., J.F.S., M.S., O.L. or A.B.) identified the eligible studies after independently evaluating all citations. Disagreements were resolved by an arbitrator (A.F.T.).

We included retrospective or prospective cohort studies and randomized controlled trials (RCTs) that reported data on the concentration of neuron-specific enolase sampled in the acute phase of care (i.e., care for a severe episodic or brief illness including both intensive or emergency care) after moderate (Glasgow Coma Scale score of 9-12) or severe (Glasgow Coma Scale score $\leq 8$ ) traumatic brain injury. Our primary outcomes were mortality and either the last reported Glasgow Outcome Scale ${ }^{23}$ or Glasgow Outcome ScaleExtended score. Studies reporting 1 or more quantitative levels of neuron-specific enolase in the serum or cerebrospinal fluid and 1 of the follow-up outcome measures after discharge from the intensive care unit (ICU) were eligible. We excluded studies in which more than half of the study population were children $(<18 \mathrm{yr}$ of age and for which the subgroup of adult patients could not be extracted), because the reference values for cerebrospinal fluid levels of neuron-specific enolase vary in this patient population. ${ }^{24}$ Studies involving less than $80 \%$ of patients with moderate or severe traumatic brain injury were also excluded, unless data specifically related to patients with moderate or severe traumatic brain injury could be extracted.

\section{Data abstraction}

Using a standardized abstraction form, pairs of reviewers (E.M., J.F.S., M.S., O.L. or A.B.) independently extracted data including study characteristics (i.e., country, number of centres involved, years of completion and publication and language), patient characteristics (i.e., age, gender, systemic injuries, pupil reaction, hypotension, hypoxemia and intracranial pressure measures), details of the traumatic brain injury (i.e., closed or penetrating, type of intracranial lesions, mechanism of injury and cerebral computed tomography [CT] scan results), treatments and interventions (i.e., neurosurgery, duration and type of mechanical ventilation, and ICU and/or hospital length of stay), laboratory aspects of the neuronspecific enolase testing (i.e., type of assay used, time period of sampling and sample type) and outcome evaluation (i.e., outcome definition, outcome evaluator and time period of outcome evaluation). If 2 articles reported data involving the same patient population, the article with the largest number of study participants was included unless discriminatory individual patient data were available. The furthest outcome assessment was retained when repeated measurements of outcomes were reported. We defined an unfavourable neurologic outcome as mortality, Glasgow Outcome Scale score of 3 or less, Glasgow Outcome Scale-Extended score of 4 or less. In our analyses, a Glasgow Outcome Scale score of 3 or less and a Glasgow Outcome Scale-Extended score of 4 or less were considered comparable unfavourable outcomes.

\section{Assessment of the risk of bias}

We developed a risk-of-bias assessment tool for prognostic studies based on the validated Quality Assessment of Diagnostic Accuracy Studies (QUADAS-2) tool, which evaluates study participation, study attrition, prognostic factor measurement, outcome measurement and confounding ${ }^{25}$ (Appendix 3, available at www.cmajopen.ca/content/4/X/E371/suppl/DC1). We used this assessment tool in a previous systematic review and meta-analysis. ${ }^{26}$

\section{Statistical analysis}

As neuron-specific enolase serum values follow a normal distribution, ${ }^{27}$ mean differences (MDs) with $95 \%$ confidence intervals (CIs) were used to evaluate the association with our primary and secondary outcomes. We resolved any uncertainties with regard to whether a study reported standard deviations or standard errors by classifying those measures according to the amplitude of the measure of central tendency in 
relation with the sample size and after comparison with other reported measures of variation. If uncertainty persisted, to prevent an incorrect rejection of the null hypothesis, we assumed the published statistics to be standard errors. Results were pooled using inverse-variance random-effects models.

We assessed statistical heterogeneity using the $I^{2}$ statistic. $^{28}$ We analyzed samples of neuron-specific enolase in serum and cerebrospinal fluid separately. Based on a priori hypotheses, we conducted subgroup and sensitivity analyses to investigate potential clinical and methodologic heterogeneity. Subgroup analyses included the time-period of outcome evaluation, sampling time, severity of traumatic brain injury, extent of associated injuries, the type of assay used and blinding. We also conducted subgroup analyses according to the risk of bias. We also conducted an a posteriori sensitivity analysis that evaluated the impact of neuronspecific enolase concentration in serum but not in plasma. We used random-effects models to generate summary estimates of mortality and Glasgow Outcome Scale scores using Review Manager version 5.0 (The Cochrane Collaboration) and SAS version 9.2 (SAS Institute Inc.). For all tests of statistical inference and CIs, we used a 2-tailed type I error rate of 5\%. The quality of the evidence for the 2 main outcomes was determined using the Grading of Recommendations Assessment, Development and Evaluation (GRADE) approach ${ }^{29}$ and GRADEpro software (available at http://gradepro.org).

\section{Results}

\section{Study identification and selection}

Our search strategy retrieved 5026 citations; 133 of which were reviewed in full text. Thirty unique studies ${ }^{30-59}(n=1321)$ published between 1983 and 2015 met our eligibility criteria (Figure 1).

\section{Study characteristics}

Five eligible studies were published in languages other than English: 2 in Japanese $(n=89)^{39,51}$ and 3 in Chinese $(n=$ 95). ${ }^{38,41,58}$ Twenty-nine studies were retrospective or prospective observational cohorts $(n=4-182)$. One study was a RCT comparing the use of hypertonic saline and isotonic saline $(n=64) .^{31}$ Twenty-four studies reported serum concentrations of neuronspecific enolase $(n=1164), 1$ study reported plasma concentration $(n=102)$ and 7 studies reported cerebrospinal fluid concentrations $(n=255) .{ }^{30,32,34,36,46,47,50}$ Three studies reported both serum and cerebrospinal fluid neuron-specific enolase concentrations. ${ }^{30,34,50}$ The earliest delay between the first traumatic brain injury and the first measurement of neuron-specific enolase obtained was as-soon-as-possible/on admission for 8 studies, ${ }^{31,35,38,40,43,47,52,59}$ up to 12 hours for 10 studies, ${ }^{32,33}$, $37,39,41,42,53,55,56,58$ up to 24 hours for 9 studies $^{30,34,44,45,48-51,54}$ and greater than 24 hours for 2 studies. ${ }^{37,46}$ Twenty-six studies used a Glasgow Outcome Scale score of 3 or less, or a Glasgow Outcome Scale-Extended score of 4 or less to define unfavourable outcome $(n=1255)$, and 14 studies reported mortality $(n=700)$; 10 of these studies $(n=719)$ reported both (Table 1$)$. Time for outcome evaluation ranged from ICU discharge up to 1 year after injury. Fifteen studies s $^{30,32,36,38,42,44,45,48-51,53-56}$ included patients with significant extracerebral injuries, whereas 11 studies ${ }^{31,33,35,37,39,40,46,47,52,58,59}$ included only isolated traumatic brain injury. In 4 studies, the presence of extracerebral injury was unknown. ${ }^{34,41,43,57}$ Additional characteristics of the included studies are reported in Table 1.

\section{Risk of bias}

A detailed evaluation of risk of bias for the included studies is presented in Figure 2. All studies had risk of bias because none reported control for confounding; 2 studies had unclear risk of bias. ${ }^{41,44}$ More than half of the studies (16, 53\%) did not report if the outcome assessors were blinded to neuronspecific enolase concentration measures. Appropriate adjustment for confounding factors was lacking in 24 studies (80\%) (Figure 2). Lost to follow-up and index tests (appropriate test to evaluate neuron-specific enolase concentrations) were at low risk of bias in 22 (73\%) and 25 (83\%) studies, respectively.

\section{Outcome measures}

\section{Blood samples}

We pooled studies reporting blood concentrations (serum or plasma) of neuron-specific enolase in relation to mortality or

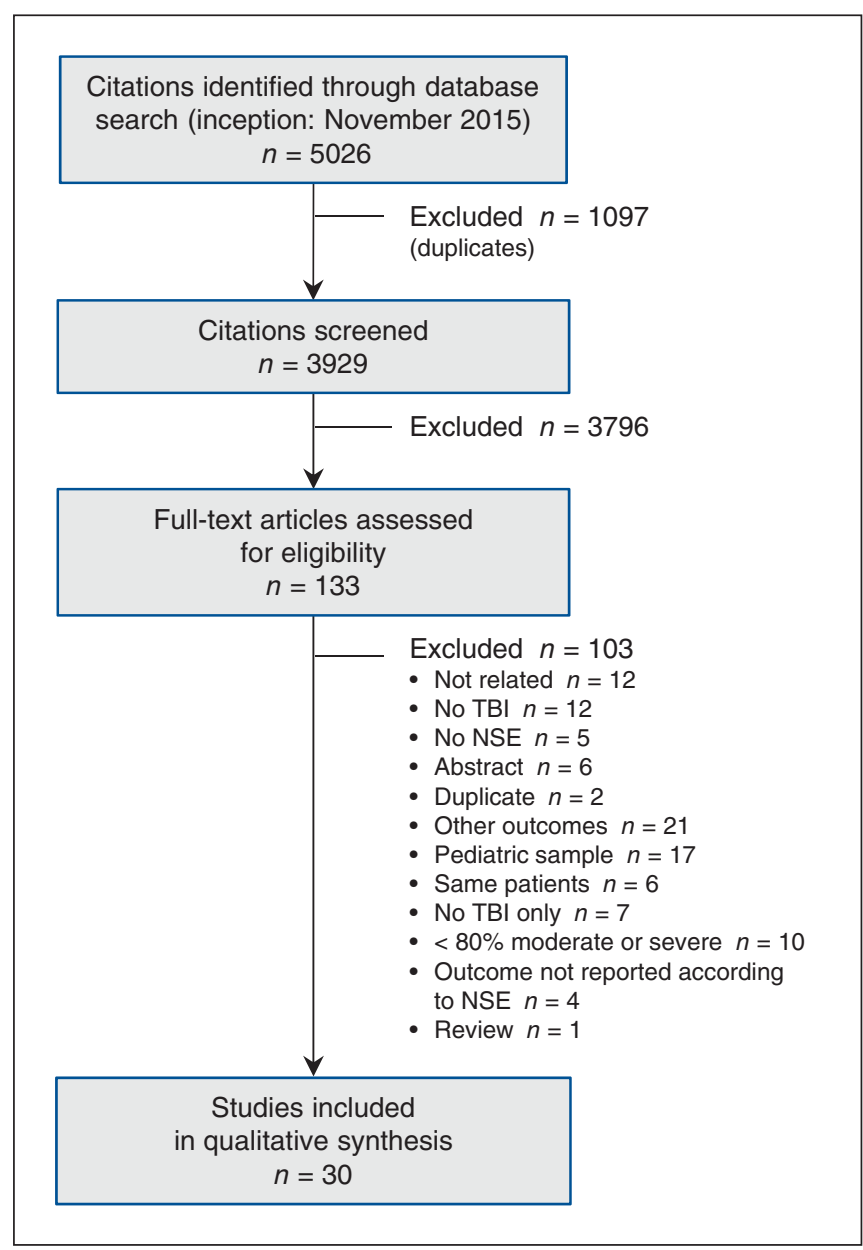

Figure 1: Flow diagram for the selection of studies. NSE = neuronspecific enolase, $\mathrm{TBI}=$ traumatic brain injury. 


\section{OPEN}

Research

unfavourable outcome. Many studies were excluded in the meta-analysis because they reported neuron-specific enolase concentration as median and interquartile range, peak con- centration or concentration unrelated to outcome. We observed a significant association between increased blood concentrations of neuron-specific enolase and mortality (10

\begin{tabular}{|c|c|c|c|c|c|c|c|}
\hline Studies & $N^{*}$ & Inclusion criteria & Age, yr & $\begin{array}{l}\text { No. of } \\
\text { patients } \\
\text { (F/M) }\end{array}$ & Severity scales & Assay & Main outcome \\
\hline Al Nimer et al. ${ }^{30}$ & 182 & $\begin{array}{l}\text { Patients with NF-L sample } \\
\text { in Traumatic Brain Injury } \\
\text { Database of Karolinska } \\
\text { Institute }\end{array}$ & $\begin{array}{l}\text { Median (range) } \\
55(15-79)\end{array}$ & $45 / 137$ & $\begin{array}{l}\text { Mean } \pm \text { SD GCS } 7 \pm 4 \\
\text { Median (IQR) ISS } 25 \text { (19-29) }\end{array}$ & $\begin{array}{l}\text { IRMA, Liaison } \\
\text { (DiaSorin) }\end{array}$ & $\begin{array}{l}\text { GOS at } 6 \text { and } \\
12 \text { mo } \\
1-3 \text { unfavourable } \\
4-5 \text { favourable }\end{array}$ \\
\hline Baker et al. ${ }^{31}$ & 64 & $\begin{array}{l}\text { GCS } \leq 8 ; \text { coma or loss of } \\
\text { consciousness because of } \\
\text { isolated blunt TBI }\end{array}$ & $\begin{array}{l}\text { Mean (range) } \\
41.4(18.3-87.9)\end{array}$ & $23 / 41$ & $\begin{array}{l}\text { Mean } \pm \text { SD GCS } \\
5.7 \pm 2.7\end{array}$ & & $\begin{array}{l}\text { Mortality, GOSE } \\
\text { and GOS at } \\
\text { hospital } \\
\text { discharge (or } \\
30 \text { d) } \\
1-3 \text { unfavourable } \\
4-5 \text { favourable }\end{array}$ \\
\hline Böhmer et al. ${ }^{32}$ & 20 & $\begin{array}{l}\text { GCS } \leq 8 \text { with abnormal brain } \\
\text { CT scan on admission; } \\
\text { ventriculostomy installed }\end{array}$ & $\begin{array}{l}\text { Mean } \pm \text { SD } \\
29 \pm 13\end{array}$ & $2 / 18$ & NR & $\begin{array}{l}\text { Elecsys } \\
\text { (Roche Diagnostics) }\end{array}$ & Mortality \\
\hline Chabok et al. ${ }^{33}$ & 28 & $\begin{array}{l}\text { GCS } \leq 8 ; \\
\text { Severe diffuse axonal injury } \\
\text { (exclusion of intra- and } \\
\text { extracranial hematoma on } \\
\text { CT); age } \geq 16 \text { yr; no severe } \\
\text { systemic injury; no } \\
\text { intoxication; no pre-existing } \\
\text { disease }\end{array}$ & $\begin{array}{l}\text { Mean } \pm \text { SD } \\
31 \pm 19\end{array}$ & $2 / 26$ & $\begin{array}{l}\text { Mean admission } \pm \text { SD } \\
\text { GCS } 6.7 \pm 1.3\end{array}$ & $\begin{array}{l}\text { ELISA } \\
\text { (Can Ag Diagnostics) }\end{array}$ & \\
\hline $\begin{array}{l}\text { Dauberschmidt } \\
\text { et al. }^{34}\end{array}$ & 9 & $\begin{array}{l}\text { Cerebral coma after severe } \\
\text { head trauma }\end{array}$ & $\begin{array}{l}\text { Mean } \pm \text { SD } \\
39.7 \pm 16.9\end{array}$ & $1 / 8$ & NR & RIA & Mortality at $1 \mathrm{mo}$ \\
\hline $\begin{array}{l}\text { Di Battista et } \\
\text { al. }{ }^{35}\end{array}$ & 85 & $\begin{array}{l}\text { GCS }<13 \text {; on-head } \\
\text { abbreviated injury score } \\
\text { (AIS) } \leq 2\end{array}$ & $\begin{array}{l}\text { Mean } \pm \text { SD } \\
45.8 \pm 21.9\end{array}$ & $19 / 66$ & $\begin{array}{l}\text { Median (range) GCS } 5(3-8) \\
\text { Mean } \pm \text { SD ISS } 23.6 \pm 11 \\
\text { Mean } \pm \text { SD AISh } 4.2 \pm 1.1\end{array}$ & $\begin{array}{l}\text { ELISA, SECTOR } \\
\text { Imager (Meso Scale } \\
\text { Diagnostics) }\end{array}$ & $\begin{array}{l}\text { Mortality and } \\
\text { GOS at } 6 \text { mo } \\
1-3 \text { unfavourable } \\
4-5 \text { favourable }\end{array}$ \\
\hline Gatson et al. ${ }^{36}$ & 18 & $\begin{array}{l}\text { GCS } \leq 8 ; \text { ventriculostomy } \\
\text { installed }\end{array}$ & $\begin{array}{l}\text { Mean } \pm \text { SD } \\
32.1 \pm 12.3\end{array}$ & $7 / 11$ & Mean \pm SD GCS $3.75 \pm 1.2$ & $\begin{array}{l}\text { ELISA (USCN Life } \\
\text { Science) }\end{array}$ & $\begin{array}{l}\text { GOSE } \\
1-4 \text { unfavourable } \\
5-8 \text { favourable }\end{array}$ \\
\hline $\begin{array}{l}\text { Gradisek et } \\
\text { al. }^{37}\end{array}$ & 84 & $\begin{array}{l}\text { GCS } \leq 8 \text { after reanimation or } \\
\text { deterioration to GCS }<8 \\
\text { after the first } 24 \mathrm{hr} \text {; isolated } \\
\text { TBI (no extracranial injury } \\
\text { with AIS } \geq 3 \text { ); no neurologic } \\
\text { disease }\end{array}$ & $\begin{array}{l}\text { Mean } \pm \text { SD } \\
46 \pm 21\end{array}$ & $11 / 73$ & $\begin{array}{l}\text { Median (IQR) GCS } 6(4-8) ; \\
\text { Median (IQR) ISS } 24(16-25)\end{array}$ & $\begin{array}{l}\text { ELISA, Liaison } \\
\text { (Sangtec Medical) }\end{array}$ & $\begin{array}{l}\text { All-cause } \\
\text { mortality and } \\
\text { GOS at } 12 \text { mo } \\
1-3 \text { unfavourable } \\
4-5 \text { favourable }\end{array}$ \\
\hline Guan et al. ${ }^{38}$ & 41 & $\begin{array}{l}\text { Admission within } 6 \text { hr after } \\
\text { injury; closed TBI; no history } \\
\text { of disease of vital organs } \\
\text { such as heart, kidney and } \\
\text { brain }\end{array}$ & $\begin{array}{l}\text { Mean (range) } \\
44(5-92)\end{array}$ & NR & NR & NR & $\begin{array}{l}\text { GOS at } 6 \text { mo } \\
1-3 \text { unfavourable } \\
4-5 \text { favourable }\end{array}$ \\
\hline Kuroiwa et al..$^{39}$ & 47 & NR & Mean 35.1 & $12 / 35$ & NR & RIA & $\begin{array}{l}\text { Mortality and } \\
\text { GOS }\end{array}$ \\
\hline Li et al. ${ }^{40}$ & 40 & $\begin{array}{l}\text { GCS } \leq 8 \text {; no severe systemic } \\
\text { injury; no heart or renal } \\
\text { failure; no severe CNS } \\
\text { infection }\end{array}$ & NR & NR & NR & $\begin{array}{l}\text { RIA (Sangtec } \\
\text { Medical) }\end{array}$ & $\begin{array}{l}\text { GOS at } 6 \text { mo } \\
1-3 \text { unfavourable } \\
4-5 \text { favourable }\end{array}$ \\
\hline Luo et al. ${ }^{41}$ & 24 & TBI & NR & NR & $\begin{array}{l}\text { GCS } \geq 13=9 ; \text { GCS } 9-12=17 \\
\text { GCS } \leq 8=24\end{array}$ & Custom & $\begin{array}{l}\text { GOS } \\
1-3 \text { unfavourable } \\
4-5 \text { favourable }\end{array}$ \\
\hline $\begin{array}{l}\text { McKeating et } \\
\text { al. }{ }^{42}\end{array}$ & 21 & TBI admitted to ICU & $\begin{array}{l}\text { Median (range) } \\
35(17-69)\end{array}$ & $4 / 17$ & $\begin{array}{l}\text { Median (range) GCS } 6 \text { (3-13); } \\
\text { Median (range) ISS } 25 \text { (9-38) }\end{array}$ & $\begin{array}{l}\text { RIA (Sangtec } \\
\text { Medical) }\end{array}$ & $\begin{array}{l}\text { GOS at } 6 \text { mo } \\
1-3 \text { unfavourable } \\
4-5 \text { favourable }\end{array}$ \\
\hline $\begin{array}{l}\text { Meissner et } \\
\text { al. } .^{43}\end{array}$ & 20 & NR & NR & NR & NR & NR & Mortality \\
\hline Meric et al. ${ }^{44}$ & 40 & $\begin{array}{l}\geq 18 \text { yr of age; presenting } \\
\text { to ED within } 24 \text { hr after } \\
\text { trauma }\end{array}$ & $\begin{array}{l}\text { Median } \\
\text { (range) } \\
31(18-88)\end{array}$ & $28 / 12$ & $\mathrm{GCS} \leq 13$ & $\begin{array}{l}\text { ECLIA (Roche } \\
\text { Diagnostics) }\end{array}$ & $\begin{array}{l}\text { Mortality and } \\
\text { GOS at } 1 \mathrm{mo}\end{array}$ \\
\hline
\end{tabular}


Table 1 (part 2 of 2): Characteristics of the included studies

\begin{tabular}{|c|c|c|c|c|c|c|c|}
\hline Studies & $N^{*}$ & Inclusion criteria & Age, yr & $\begin{array}{l}\text { No. of } \\
\text { patients } \\
\text { (F/M) }\end{array}$ & Severity scales & Assay & Main outcome \\
\hline $\begin{array}{l}\text { Olivecrona et } \\
\text { al. }{ }^{45}\end{array}$ & 48 & $\begin{array}{l}\text { GCS } \leq 8 ; 15-70 \text { yr of age; } \\
\text { first recorded } \mathrm{CPP}>10 \mathrm{~mm} \\
\mathrm{Hg} ; \text { arrival }<24 \mathrm{hr} \text { after TBI }\end{array}$ & $\begin{array}{l}\text { Median (range) } \\
31(15-63)\end{array}$ & $17 / 31$ & $\begin{array}{l}\text { Median (range) ISS } 29(9-50) \text {; } \\
\text { Median (range) APACHE II } 21 \\
(12-32)\end{array}$ & $\begin{array}{l}\text { LIA (DiaSorin } \\
\text { Diagnostica) }\end{array}$ & $\begin{array}{l}\text { GOS at } 3 \text { and } 12 \\
\text { mo } \\
1-3 \text { unfavourable } \\
4-5 \text { favourable }\end{array}$ \\
\hline Persson et al. ${ }^{46}$ & 4 & NR & NR & NR & NR & Custom & $\begin{array}{l}\text { GOS at hospital } \\
\text { discharge } \\
1-3 \text { unfavourable } \\
4-5 \text { favourable }\end{array}$ \\
\hline Pleines et al. ${ }^{47}$ & 13 & $\begin{array}{l}\text { GCS } \leq 8 \text { admission; isolated } \\
\text { TBI }\end{array}$ & $\begin{array}{l}\text { Mean (range) } \\
36(16-67)\end{array}$ & NR & NR & $\begin{array}{l}\text { ELISA (Wallac } \\
\text { Sverige AB) }\end{array}$ & $\begin{array}{l}\text { GOS between } 3 \\
\text { and } 6 \text { mo }\end{array}$ \\
\hline Raabe et al. ${ }^{48}$ & 44 & Severe head injury & $\begin{array}{l}\text { Median (range) } \\
41(16-83)\end{array}$ & $11 / 33$ & Median (range) GCS 5 (3-8) & $\begin{array}{l}\text { RIA (Sangtec } \\
\text { Medical) }\end{array}$ & $\begin{array}{l}\text { GOS at } 6 \text { mo } \\
1-3 \text { unfavourable } \\
4-5 \text { favourable }\end{array}$ \\
\hline Raabe et al. ${ }^{49}$ & 82 & $\begin{array}{l}\text { GCS } \leq 8 \text { postresuscitation; } \\
\text { admitted neurosurgical ICU }\end{array}$ & $\begin{array}{l}\text { Median (range) } \\
38(16-85)\end{array}$ & $16 / 66$ & NR & $\begin{array}{l}\text { RIA (Sangtec } \\
\text { Medical) }\end{array}$ & $\begin{array}{l}\text { GOS at } 6 \text { mo } \\
1-3 \text { unfavourable } \\
4-5 \text { favourable }\end{array}$ \\
\hline Ross et al. ${ }^{50}$ & 9 & $\begin{array}{l}\text { Admitted to } \mathrm{ICU} \leq 24 \mathrm{~h} \text { after } \\
\text { TBI }\end{array}$ & $\begin{array}{l}\text { Median (range) } \\
21.5(4-70)\end{array}$ & $2 / 7$ & Median (range) GCS 6 (3-9) & RIA & $\begin{array}{l}\text { Mortality at ICU } \\
\text { discharge } \\
\text { GOS }\end{array}$ \\
\hline $\begin{array}{l}\text { Sawauchi et } \\
\text { al. }^{51}\end{array}$ & 41 & Consecutive TBI & NR & NR & $\mathrm{GCS}>8=30 ; \mathrm{GCS} \leq 9=11$ & NR & $\begin{array}{l}\text { GOS at } 3 \text { mo } \\
1-3 \text { unfavourable } \\
4-5 \text { favourable }\end{array}$ \\
\hline Stein et al. ${ }^{52}$ & 24 & $\begin{array}{l}\text { Age > } 17 \text { yr; admission } \\
\text { within the first } 6 \mathrm{hr} \text { after } \\
\text { injury; GCS score }<9 \text { on } \\
\text { admission; isolated TBI (no } \\
\text { extracranial injury with AIS } \geq \\
\text { 4); placement of a clinically } \\
\text { indicated ICP monitor } \\
\text { performed }\end{array}$ & $\begin{array}{l}\text { Mean } \pm \text { SD } \\
30.7 \pm 12.3 \\
\text { Range 19-64 }\end{array}$ & $3 / 21$ & Mean \pm SD GCS $5.8 \pm 3.4$ & $\begin{array}{l}\text { ELISA (Biovendor } \\
\text { Candor) }\end{array}$ & $\begin{array}{l}\text { GOSE at } 3,6 \text { and } \\
12 \text { mo } \\
1-4 \text { unfavourable } \\
5-8 \text { favourable }\end{array}$ \\
\hline Vos et al. ${ }^{53}$ & 78 & $\begin{array}{l}\text { GCS } \leq 8 \text { postresuscitation } \\
\text { admitted } \leq 36 \text { hr after injury; } \\
\text { closed TBI; blood sample } \\
\text { taken; long-term follow-up }\end{array}$ & $\begin{array}{l}\text { Median (range) } \\
32(15-81)\end{array}$ & $24 / 61$ & $\begin{array}{l}\text { Median (range) GCS } 4(3-8) ; \\
\text { Median (range) ISS } 29(9-75)\end{array}$ & $\begin{array}{l}\text { LIA (Sangtec } \\
\text { Medical) }\end{array}$ & $\begin{array}{l}\text { Mortality and } \\
\text { GOS at } \\
6 \text { mo } \\
1-3 \text { unfavourable } \\
4-5 \text { favourable }\end{array}$ \\
\hline Wang et al..$^{54}$ & 34 & $\begin{array}{l}\text { Admitted to neurosurgery } \\
<24 \mathrm{hr} \text { after injury }\end{array}$ & Range 15-73 & $15 / 19$ & NR & $\begin{array}{l}\text { ECLIA (Roche } \\
\text { Diagnostics) }\end{array}$ & $\begin{array}{l}\text { GOS at } 3 \text { mo } \\
1-3 \text { unfavourable } \\
4-5 \text { favourable }\end{array}$ \\
\hline $\begin{array}{l}\text { Woertgen et } \\
\text { al. }^{55}\end{array}$ & 30 & $\begin{array}{l}\text { GCS } \leq 8 \text {; admitted between } \\
1 \text { and } 6 \text { hr after injury; no } \\
\text { spinal cord injury; no history } \\
\text { of neurologic disease; no } \\
\text { resuscitation or shock }\end{array}$ & $\begin{array}{l}\text { Mean (range) } \\
32(17-73)\end{array}$ & $7 / 23$ & NR & $\begin{array}{l}\text { ELISA (Wallac } \\
\text { Sverige AB) }\end{array}$ & $\begin{array}{l}\text { GOS at hospital } \\
\text { discharge } \\
\text { 1-3 unfavourable } \\
4-5 \text { favourable }\end{array}$ \\
\hline $\begin{array}{l}\text { Yamazaki et } \\
\text { al. }^{56}\end{array}$ & 17 & $\begin{array}{l}\text { No severe hypoxia or } \\
\text { systemic hypotension }\end{array}$ & $\begin{array}{l}\text { Mean (range) } \\
45(14-91)\end{array}$ & $5 / 20$ & $\mathrm{GCS}<8=9 ; \mathrm{GCS} \geq 8=16$ & NR & $\begin{array}{l}\text { Mortality at } \\
\text { hospital } \\
\text { discharge (mean } \\
22 \text { d) }\end{array}$ \\
\hline Yan et al. ${ }^{57}$ & 42 & $\begin{array}{l}\text { GCS } \leq 8 \text {; extraventricular } \\
\text { drain }\end{array}$ & $\begin{array}{l}\text { Median (range) } \\
29(16-23)\end{array}$ & $10 / 32$ & $\begin{array}{l}\text { Median (range) GCS } 5(3-10) \\
\text { Median (IQR) ISS } 36(27-43)\end{array}$ & $\begin{array}{l}\text { ELISA (CanAg } \\
\text { Diagnostics) }\end{array}$ & $\begin{array}{l}\text { GOSE at } 6 \text { mo } \\
1-4 \text { unfavourable } \\
5-8 \text { favourable }\end{array}$ \\
\hline Zhan et al. ${ }^{58}$ & 30 & $\begin{array}{l}\text { GCS } \leq 8 \text { admission; no } \\
\text { severe systemic injury; no } \\
\text { severe cardiac ischemia; no } \\
\text { renal failure; no severe CNS } \\
\text { infection }\end{array}$ & Range 26-64 & $12 / 18$ & NR & NR & $\begin{array}{l}\text { GOS at } 1 \text { mo } \\
1-3 \text { unfavourable } \\
4-5 \text { favourable }\end{array}$ \\
\hline Zhang et al. ${ }^{59}$ & 102 & $\begin{array}{l}\text { Isolated head trauma; } \\
\text { postresuscitation GCS } \leq 8 \\
\text { age } \geq 18 \mathrm{yr} ; \text { admission } \\
\text { time }>6 \mathrm{hr}\end{array}$ & $\begin{array}{l}\text { Mean } \pm \text { SD } \\
40.5 \pm 15.3\end{array}$ & $34 / 68$ & Median (range) GCS 5 (3-8) & $\begin{array}{l}\text { ELISA (Phoenix } \\
\text { Pharmaceuticals) }\end{array}$ & $\begin{array}{l}\text { GOSE at } 6 \text { mo } \\
1-4 \text { unfavourable } \\
5-8 \text { favourable }\end{array}$ \\
\hline \multicolumn{8}{|c|}{$\begin{array}{l}\text { Note: AIS = abbreviated injury score, AISh = abbreviated injury score head, APACHE II = acute physiology and chronic health evaluation II, CNS = central nervous system, } \\
\mathrm{CPP}=\text { cerebral perfusion pressure, } \mathrm{CT}=\text { computed tomography, ED = emergency department, ECLIA = electrochemiluminescence immunoassay, ELISA = enzyme-linked } \\
\text { immunosorbent assay, GCS = Glasgow Coma Scale, GOS = Glasgow Outcome Scale, GOSE = Glasgow Outcome Scale-Extended, ICP = intracranial pressure, ICU = } \\
\text { intensive care unit, IQR = interquartile range, IRMA = immunoradiometric assay, ISS = injury severity score, LIA = luminescence immunoassay, NF-L = neurofilament light, } \\
\mathrm{NR}=\text { not reported, RIA = radioimmunoassay, } \mathrm{SD}=\text { standard deviation, TBI = traumatic brain injury. } \\
{ }^{*} \text { Number of patients included in the analysis (may be different from the number of patients included in the study when data specific to our population of interest could be } \\
\text { extracted). }\end{array}$} \\
\hline
\end{tabular}




\section{OPEN}

studies, $n=474 ; \mathrm{MD} 18.46 \mu \mathrm{g} / \mathrm{L}$ [95\% CI 10.81 to $26.11 \mu \mathrm{g} / \mathrm{L}] ; I^{2}=81 \%$ ) (Figure 3 ). Increased blood neuronspecific enolase levels were also associated with a Glasgow Outcome Scale score of 3 or less [14 studies, $n=603$ : MD $17.25 \mu \mathrm{g} / \mathrm{L}$ (95\% CI 11.42 to $23.07 \mu \mathrm{g} / \mathrm{L}) ; I^{2}=82 \%$ ] (Figure 4).
We performed planned sensitivity and subgroup analyses (Table 2), although many could not be done because of data unavailability. Subgroup analyses evaluating biochemical analysis seemed to explain part of the observed heterogeneity. An a posteriori sensitivity analysis evaluating studies reporting

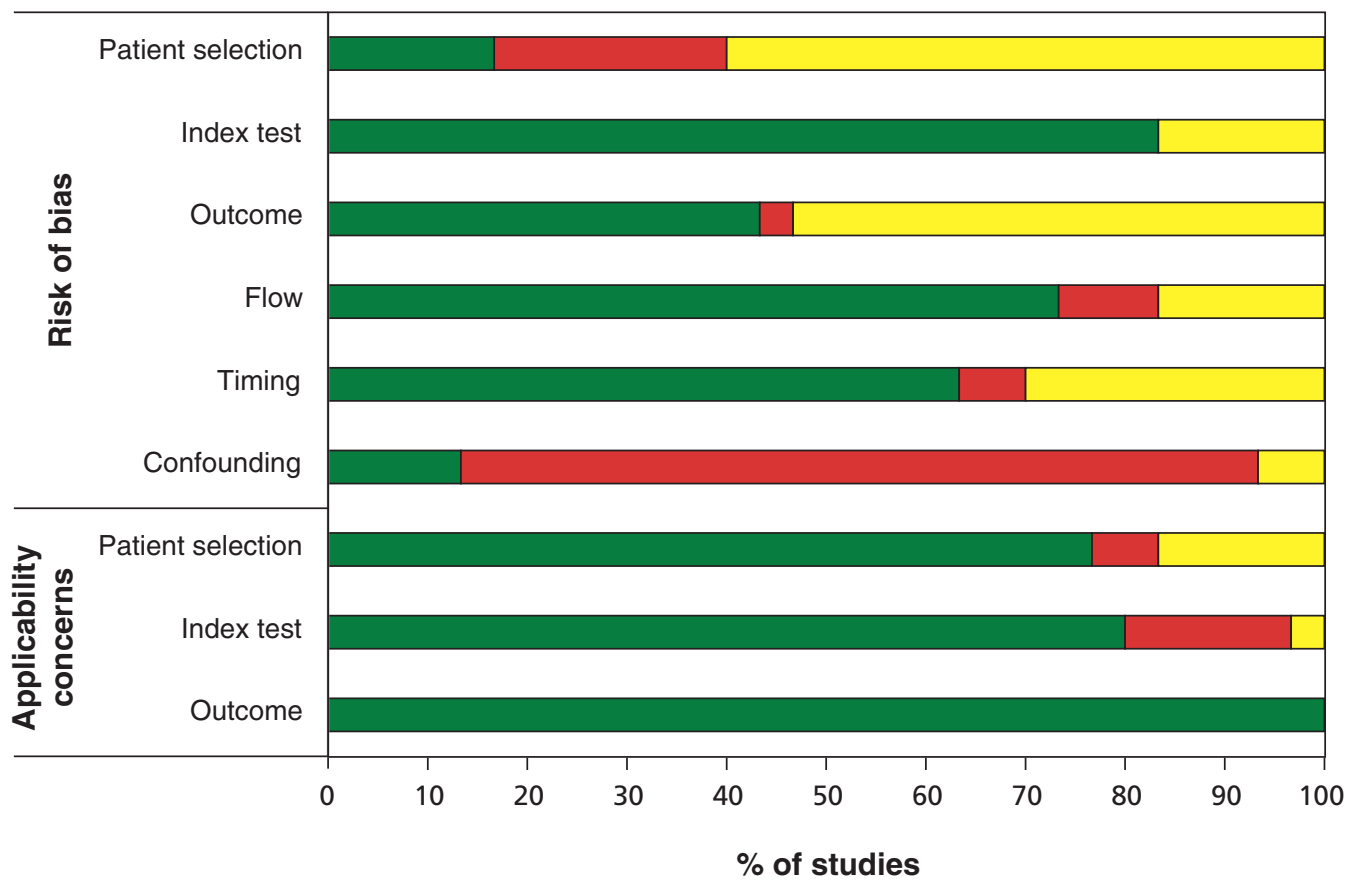

Low $\square$ High $\square$ Unclear

Figure 2: Risk of bias and applicability concerns of included studies.

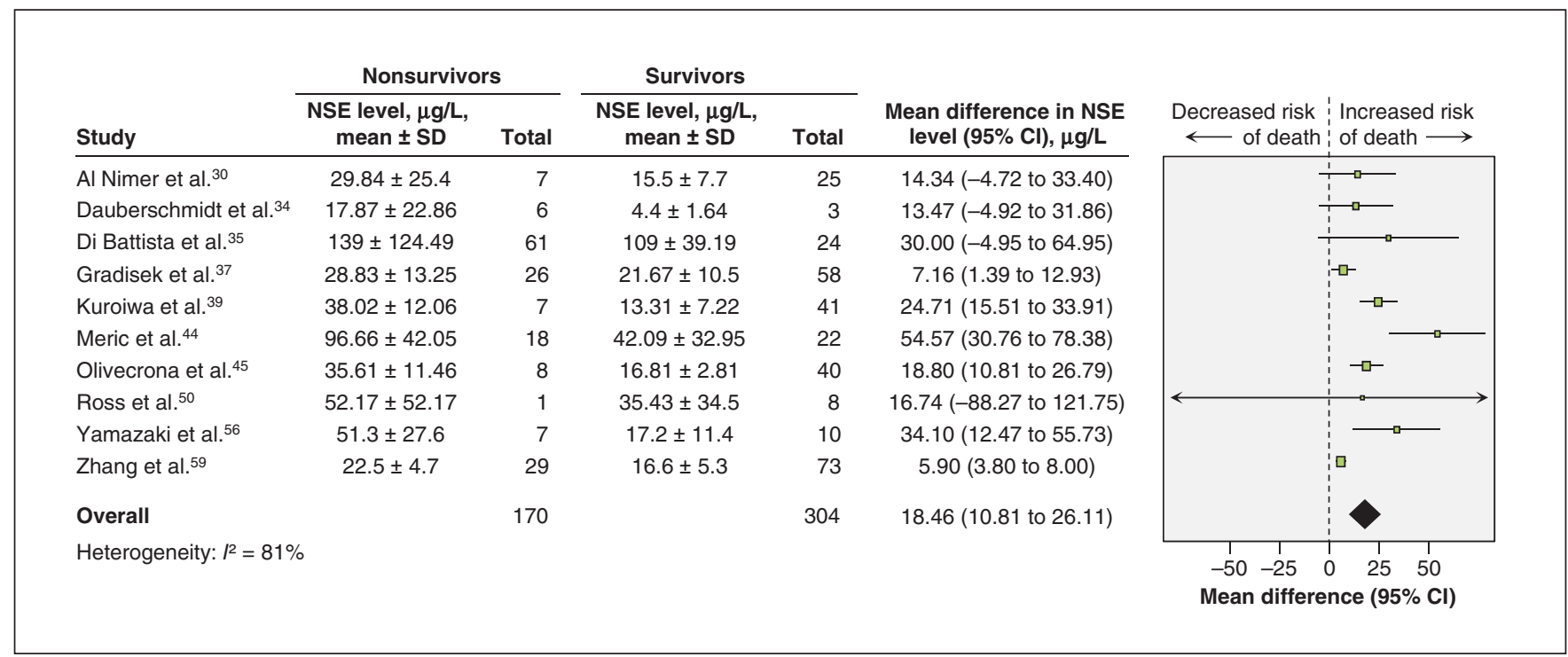

Figure 3: Mean differences of neuron-specific enolase blood levels in patients with moderate or severe traumatic brain injury, by mortality. A mean difference above zero indicates an increased risk of death. $\mathrm{Cl}=$ confidence interval, IV = inverse variance, NSE $=$ neuron-specific enolase, SD $=$ standard deviation. 


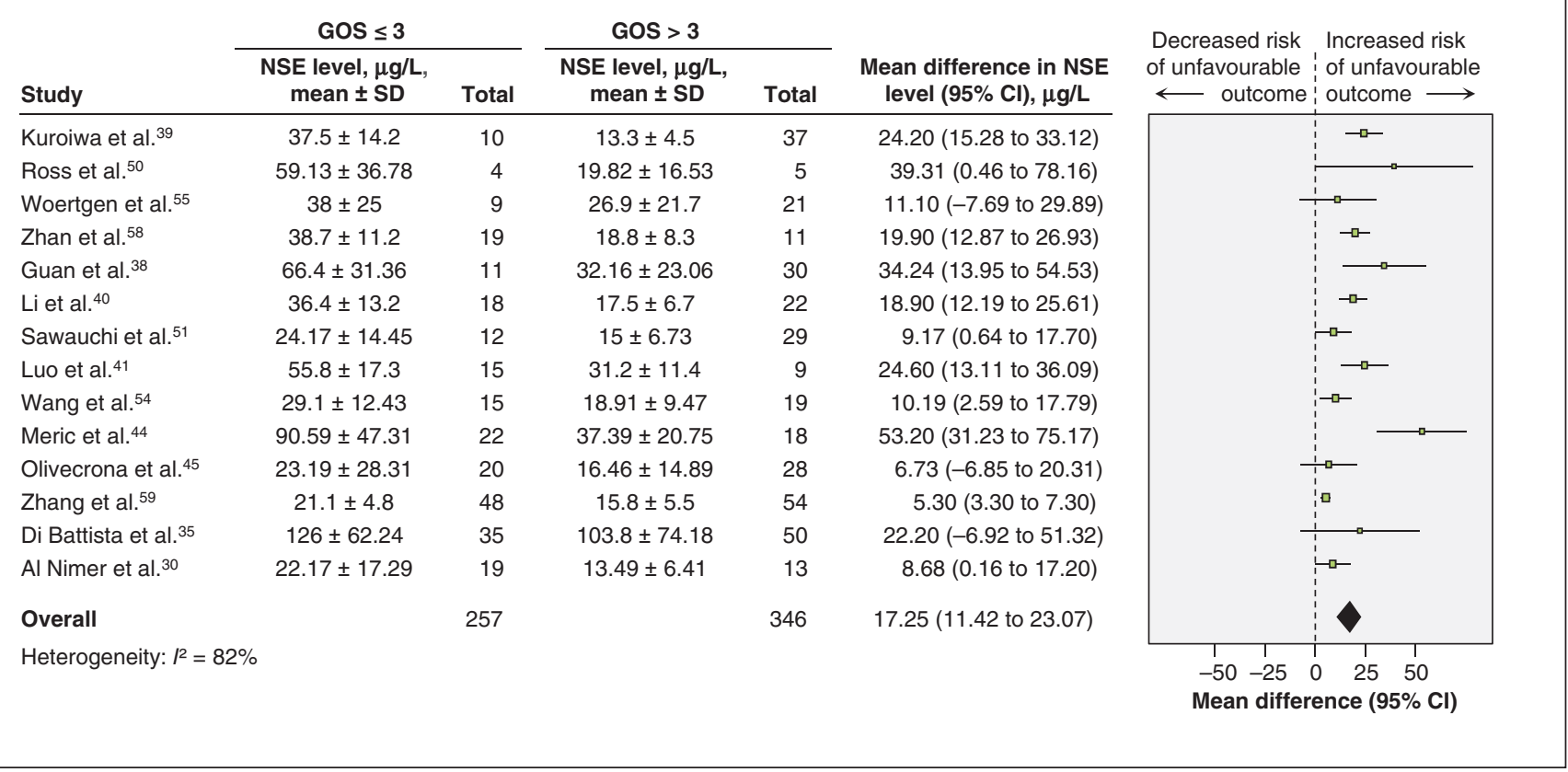

Figure 4: Mean differences of neuron-specific enolase blood levels in patients with moderate or severe traumatic brain injury, by neurologic outcome (defined by the Glasgow Outcome Scale Score). A mean difference above zero indicates an increased risk of poor neurologic outcome. $\mathrm{Cl}=$ confidence interval, GOS = Glasgow outcome scale, IV = inverse variance, NSE = neuron-specific enolase, SD = standard deviation .

neuron-specific enolase serum concentration (excluding those studies using plasma concentration) explained most of the statistical heterogeneity observed (Table 3), and more specifically when taking into consideration evaluation time, sampling time, biochemical analysis, severity of traumatic brain injury and isolated traumatic brain injuries (Table 3).

\section{Cerebral spinal fluid samples}

Of the 7 studies evaluating cerebral spinal fluid, only 2 reported neuron-specific enolase in a way that results could be integrated in a meta-analysis. ${ }^{29,33}$ Because there were fewer than 3 studies, we did not pool these studies for meta-analysis.

\section{Discrimination thresholds}

In 7 studies that presented individual data, 4 reported serum neuron-specific enolase concentrations $3^{30,42,44,50}$ and 6 reported cerebrospinal fluid measurements. ${ }^{30,32,34,46,47,50}$ Between-study variation in reported data made determination of an accurate threshold for poor outcome based on neuron-specific enolase value impractical. Various serum discrimination thresholds were suggested, ranging from 20 to $51.8 \mu \mathrm{g} / \mathrm{L}$ for mortality and 9.5 to $100 \mu \mathrm{g} / \mathrm{L}$ for unfavourable outcomes, ${ }^{32,38}$, $40,44,45,49,53,56,58,59$ and varied depending on the delay of the sampling after the traumatic brain injury and the definition of a relevant sensibility or specificity (Table 4).

\section{Discussion}

We found increased serum concentrations of neuron-specific enolase to be associated with unfavourable neurologic out- come defined as mortality or a Glasgow Outcome Scale score of 3 or less. The summary effect measures were marked by considerable heterogeneity. We could not determine threshold values associated with unfavourable prognosis.

In a systematic review that evaluated the prognostic value of neuron-specific enolase following acute ischemic stroke, ${ }^{60}$ an association between serum concentrations of neuronspecific enolase and the severity of the stroke was identified. However, the relationship between serum neuron-specific enolase concentrations and functional outcomes was unclear. In the population of patients with traumatic brain injury, studies have also reported a correlation between the presenting Glasgow Coma Scale, ${ }^{61}$ severity of parenchymal brain damage and serum concentrations of neuron-specific enolase, ${ }^{16,62}$ which provided an indication of the potential diagnostic value of neuron-specific enolase. Consistent with our results, a systematic review showed an association of serum concentrations of neuron-specific enolase with functional outcomes following cardiac arrest, ${ }^{17,62}$ although it was not as accurate as for serum concentrations of S-100 $\beta$ protein. ${ }^{17}$ Results of our systematic review are comparable to a previous meta-analysis on S-100 $\beta$ protein in which we observed significant prognostic value of $\mathrm{S}-100 \beta$ measures in patients with moderate and severe traumatic brain injury, albeit neuronspecific enolase appears to be imprecise. ${ }^{26}$ Precision of neuronspecific enolase increases when biochemical assay, sample and outcome times, and patient characteristics are similar, and this should be considered in future trials.

The lack of cerebral specificity of neuron-specific enolase as compared with other biomarkers, such as the $S-100 \beta$ 


\section{OPEN}

Research

Table 2: Blood sample subgroup analyses, by outcome

\begin{tabular}{|c|c|c|c|c|}
\hline Outcome & No. of studies & No. of patients & Mean difference $(95 \% \mathrm{Cl})$ & $P^{2}$ \\
\hline \multicolumn{5}{|l|}{ Mortality } \\
\hline \multicolumn{5}{|l|}{ Evaluation time } \\
\hline ICU & 0 & - & - & - \\
\hline $1 \mathrm{mo}$ & 3 & 66 & 33.09 (9.67 to 56.51$)$ & 73 \\
\hline $3 \mathrm{mo}$ & 0 & - & - & - \\
\hline $6 \mathrm{mo}$ & 2 & 80 & - & - \\
\hline $12 \mathrm{mo}$ & 2 & 132 & - & - \\
\hline Unclear & 3 & 84 & $22.71(14.45$ to 30.97$)$ & 0 \\
\hline \multicolumn{5}{|c|}{ Sampling time, $\mathrm{hr}$} \\
\hline Up to 12 & 5 & 336 & 15.11 (6.29 to 23.93$)$ & 83 \\
\hline Up to 24 & 5 & 138 & 22.86 (9.66 to 36.06$)$ & 56 \\
\hline \multicolumn{5}{|l|}{ Type of sample } \\
\hline Venous & 5 & 253 & 25.53 (6.54 to 44.53$)$ & 84 \\
\hline Blood NS & 5 & 221 & 16.13 (7.63 to 24.62$)$ & 65 \\
\hline \multicolumn{5}{|c|}{ Biochemical analysis } \\
\hline $\mathrm{RIA}$ & 4 & 83 & $23.89(16.22$ to 31.05$)$ & 0 \\
\hline LIA & 1 & 48 & - & - \\
\hline ELISA & 3 & 271 & 6.12 (4.15 to 8.09$)$ & 0 \\
\hline ECLIA & 0 & - & - & - \\
\hline Other & 2 & 72 & - & - \\
\hline \multicolumn{5}{|c|}{ Minimal TBI severity } \\
\hline Mild & 2 & 49 & - & - \\
\hline Moderate & 2 & 125 & - & - \\
\hline Severe & 6 & 268 & 13.30 (5.92 to 20.67$)$ & 79 \\
\hline \multicolumn{5}{|l|}{ Isolated TBI } \\
\hline Isolated & 3 & 235 & $17.07(0.29$ to 33.85$)$ & 88 \\
\hline Nonisolated & 5 & 198 & 24.35 (9.70 to 39.00$)$ & 81 \\
\hline Unclear & 2 & 41 & - & - \\
\hline \multicolumn{5}{|l|}{ GOS or GOSE } \\
\hline \multicolumn{5}{|l|}{ Evaluation time } \\
\hline ICU & 1 & 30 & - & - \\
\hline $1 \mathrm{mo}$ & 2 & 70 & - & - \\
\hline $3 \mathrm{mo}$ & 2 & 75 & - & - \\
\hline $6 \mathrm{mo}$ & 4 & 268 & 17.19 (4.82 to 29.55$)$ & 87 \\
\hline $12 \mathrm{mo}$ & 1 & 48 & - & - \\
\hline Unclear & 4 & 113 & 16.54 (7.85 to 25.22$)$ & 52 \\
\hline \multicolumn{5}{|c|}{ Sampling time, $\mathrm{hr}$} \\
\hline Up to 12 & 8 & 400 & 17.49 (9.76 to 25.22$)$ & 85 \\
\hline Up to 24 & 6 & 204 & 14.97 (5.80 to 24.14$)$ & 71 \\
\hline \multicolumn{5}{|l|}{ Type of sample } \\
\hline Venous & 7 & 372 & 16.18 (8.41 to 23.95$)$ & 87 \\
\hline Blood NS & 7 & 232 & $16.13(9.00$ to 23.26$)$ & 47 \\
\hline \multicolumn{5}{|c|}{ Biochemical analysis } \\
\hline RIA & 3 & 97 & 17.91 (12.59 to 23.23$)$ & 0 \\
\hline LIA & 1 & 48 & - & - \\
\hline ELISA & 5 & 282 & 6.26 (4.31 to 8.20$)$ & 79 \\
\hline ECLIA & 1 & 34 & - & - \\
\hline Other & 4 & 143 & $15.22(10.74$ to 19.70$)$ & 83 \\
\hline \multicolumn{5}{|c|}{ Minimal TBI severity } \\
\hline Mild & 4 & 148 & 11.61 (4.99 to 18.32$)$ & 46 \\
\hline Moderate & 2 & 125 & - & - \\
\hline Severe & 8 & 322 & 14.57 (7.36 to 21.77$)$ & 83 \\
\hline \multicolumn{5}{|l|}{ Isolated TBI } \\
\hline Isolated & 6 & 346 & 13.80 (6.67 to 20.93$)$ & 84 \\
\hline Nonisolated & 7 & 226 & 22.42 (11.15 to 33.68$)$ & 72 \\
\hline Unclear & 1 & 32 & - & - \\
\hline
\end{tabular}


Table 3: Sensitivity analyses of studies reporting neuron-specific enolase serum concentration (excluding plasma concentration), by outcome

\begin{tabular}{|c|c|c|c|c|}
\hline Outcome & No. of studies & No. of patients & Mean difference $(95 \% \mathrm{Cl})$ & $P^{2}$ \\
\hline \multicolumn{5}{|l|}{ Mortality } \\
\hline Overall & 9 & 372 & $21.49(12.57$ to 30.41$)$ & 70 \\
\hline \multicolumn{5}{|l|}{ Evaluation time } \\
\hline $6 \mathrm{mo}$ & 1 & 85 & - & - \\
\hline \multicolumn{5}{|l|}{ Sampling time } \\
\hline Up to $12 \mathrm{hr}$ & 4 & 234 & 21.00 (6.67 to 35.32$)$ & 80 \\
\hline \multicolumn{5}{|l|}{ Type of sample } \\
\hline Venous & 4 & 151 & 32.31 (13.76 to 50.85$)$ & 59 \\
\hline \multicolumn{5}{|c|}{ Biochemical analysis } \\
\hline ELISA & 2 & 169 & - & - \\
\hline \multicolumn{5}{|c|}{ Minimal TBI severity } \\
\hline Severe & 5 & 166 & 15.99 (7.59 to 24.39$)$ & 63 \\
\hline \multicolumn{5}{|l|}{ Isolated TBI } \\
\hline Isolated & 2 & 133 & - & - \\
\hline \multicolumn{5}{|l|}{ GOS or GOSE } \\
\hline Overall & 13 & 501 & 18.21 (12.95 to 23.47$)$ & 63 \\
\hline \multicolumn{5}{|l|}{ Evaluation time } \\
\hline $6 \mathrm{mo}$ & 3 & 166 & 20.49 (14.27 to 26.72$)$ & 0 \\
\hline \multicolumn{5}{|l|}{ Sampling time } \\
\hline Up to $12 \mathrm{hr}$ & 7 & 298 & 19.39 (15.59 to 23.20$)$ & 0 \\
\hline \multicolumn{5}{|l|}{ Type of sample } \\
\hline Venous & 6 & 270 & 18.35 (10.68 to 26.02$)$ & 72 \\
\hline \multicolumn{5}{|c|}{ Biochemical analysis } \\
\hline ELISA & 4 & 180 & 23.34 (14.89 to 31.79$)$ & 0 \\
\hline \multicolumn{5}{|c|}{ Minimal TBI severity } \\
\hline Severe & 7 & 229 & 18.01 (14.08 to 21.94$)$ & 6 \\
\hline \multicolumn{5}{|l|}{ Isolated TBI } \\
\hline Isolated & 5 & 244 & 16.55 (12.47 to 20.63$)$ & 11 \\
\hline
\end{tabular}

protein or glial fibrillary acidic protein, has been recently questioned $^{63}$ and identified as a potential barrier to its clinical use. The serum concentration of neuron-specific enolase is known to be elevated in patients with certain types of lung cancer, ${ }^{64}$ pulmonary diseases ${ }^{65}$ and in the presence of renal failure ${ }^{66}$ Hemolysis was also observed to increase the concentration of neuron-specific enolase in serum and cerebrospinal fluid samples ${ }^{67}$ because of its presence in erythrocytes. ${ }^{68} \mathrm{~A}$ concomitant substantial extracerebral injury could theoretically lead to an overestimation of the severity of a patient's cerebral injury and to a more somber prognosis. Nonetheless, $18(60 \%)$ of the studies we considered in our systematic review did not exclude patients with substantial extracerebral trauma, and yet we obtained significant mean differences. Although extracerebral injuries may substantially impact serum measurements of neuron-specific enolase in patients with mild traumatic brain injury, it may not be relevant in our population of interest. Indeed, as opposed to mild traumatic brain injury, the proportion of increased serum concentration of neuron-specific enolase owing to extracerebral injuries is likely much lower and perhaps even negligible in more severe brain injuries.

A systematic review on the same topic was published while we were completing our study. ${ }^{18}$ Although the authors had comparable conclusions, we noted important limitations, including methodological flaws affecting the findings and the level of evidence. First, the search strategy was not exhaustive; we identified 11 additional publications, including 4 in languages other than English, thus reducing the possibility of a language bias. Moreover, the authors used a predetermined cut-off point to calculate sensitivity and specificity based on Glasgow Outcome Scale data from 2 studies, a cut-off that was not supported in studies evaluating mortality. In addition, the 


\section{OPEN}

Research

Table 4: Neuron-specific enolase serum level cut-off values, sensitivity and specificity from included studies, by outcome

\begin{tabular}{|c|c|c|c|}
\hline Outcome & $\begin{array}{l}\text { Cut-off values } \\
(\mu \mathrm{g} / \mathrm{L})\end{array}$ & Sensitivity (\%) & Specificity (\%) \\
\hline \multicolumn{4}{|l|}{ Mortality } \\
\hline Yamazaki et al. ${ }^{56}$ & 20 & 100 & 73 \\
\hline Vos et al. ${ }^{53}$ & 21.7 & 85 & 48 \\
\hline Olivecrona et al. ${ }^{45}$ & 11.6 & 100 & 45 \\
\hline Chabok et al. ${ }^{33}$ & 51.8 & 100 & 100 \\
\hline Zhang et al. ${ }^{59}$ & 17.6 & 93 & 62 \\
\hline \multicolumn{4}{|c|}{ Glasgow Outcome Scale $\leq 3$} \\
\hline Raabe et al. ${ }^{48}$ & 100 & 9 & 96 \\
\hline Guan et al. ${ }^{38}$ & 60 & 54 & 96 \\
\hline Zhan et al. ${ }^{58}$ & 30 & 67 & 83 \\
\hline Li et al. ${ }^{40}$ & 30 & 67 & 77 \\
\hline Vos et al. ${ }^{53}$ & 21.7 & 80 & 55 \\
\hline Olivecrona et al. ${ }^{45}$ & 9.5 & 87 & 36 \\
\hline Meric et al. ${ }^{44}$ & 20.5 & 87 & 82 \\
\hline Zhang et al. ${ }^{59}$ & 16.4 & 87 & 82 \\
\hline
\end{tabular}

sensitivity at this cut-off point never reached $90 \%$ for the Glasgow Outcome Scale. They also assumed a right-skewed distribution of the data, but did not transform their data. In our meta-analysis, we assumed a normal distribution considering that 1 study specified the normal distribution of the neuronspecific enolase concentrations.

Cerebrospinal fluid concentrations of neuron-specific enolase are thought to more accurately reflect central nervous system damage than serum concentrations, especially in acute neurologic conditions such as encephalitis and neurocysticercosis. ${ }^{69}$ Suboptimal correlation between cerebrospinal fluid and serum concentrations of neuron-specific enolase has been observed. ${ }^{70}$ Although we did not observe an obvious difference between serum and cerebrospinal fluid samples according to reported central and dispersion measurements, data from studies having studied cerebrospinal fluid samples could not be used in pooled analyses because of the insufficient number of studies.

Strengths of our systematic review and meta-analysis include adherence to a protocol developed according to high methodologic standards. We used a tested search strategy for prognostic studies $^{21,22}$ and consulted multiple databases without language restriction. This approach allowed us to be exhaustive and provide comprehensive results. Our rigorous methods were based on current guidelines for both the conduct and the reporting of systematic reviews and meta-analyses. ${ }^{19,20}$

\section{Limitations}

The strength of our conclusions is limited by the quality of included studies, which we assessed according to the reported methodological quality and risk of bias. We also observed significant statistical heterogeneity for both mortality and Glasgow Outcome Scale scores; however, owing to the limited number of studies, we could not adequately explore the sources of this heterogeneity. This is of particular importance because exploration through subgroup analyses would allow us to better understand the constraints of using neuron-specific enolase as a prognostic tool.

\section{Conclusion}

We observed a significant positive association between serum concentrations of neuron-specific enolase and unfavourable outcome (mortality or a Glasgow Outcome Scale score $\leq 3$ ) after moderate or severe traumatic brain injury. However, we observed statistical heterogeneity that was partly explained by the type of sample and the timing of outcome assessment. Optimal neuron-specific enolase threshold values for unfavourable clinical outcomes still remain unknown. Further research must focus on understanding the optimal timing of assessment after injury and on finding accurate threshold values to inform the prediction of long-term outcome, coupled with multimodal prediction models, and assist with decisions pertaining to withdrawal of life-sustaining therapies.

\section{References}

1. Ghajar J. Traumatic brain injury. Lancet 2000;356:923-9.

2. Myburgh JA, Cooper DJ, Finfer SR, et al. Epidemiology and 12-month outcomes from traumatic brain injury in Australia and New Zealand. 7 Trauma 2008;64:854-62.

3. Langlois JA, Rutland-Brown W, Wald MM. The epidemiology and impact of traumatic brain injury: a brief overview. F Head Trauma Rehabil 2006;21:375-8.

4. Selassie AW, Zaloshnja E, Langlois JA, et al. Incidence of long-term disability following traumatic brain injury hospitalization, United States, 2003. 7 Head Trauma Rehabil 2008;23:123-31.

5. Turgeon AF, Lauzier F, Simard JF, et al. Mortality associated with withdrawal of life-sustaining therapy for patients with severe traumatic brain injury: a Canadian multicentre cohort study. CMA7 2011;183:1581-8.

6. Perel P, Wasserberg J, Ravi RR, et al. Prognosis following head injury: a survey of doctors from developing and developed countries. 7 Eval Clin Pract 2007;13:464-5.

7. Marshall LF, Marshall SB, Klauber MR, et al. The diagnosis of head injury requires a classification based on computed axial tomography. 7 Neurotrauma 1992;9(Suppl 1):S287-92. 
8. Murray GD, Butcher I, McHugh GS, et al. Multivariable prognostic analysis in traumatic brain injury: results from the IMPACT study. 7 Neurotrauma 2007;24:329-37

9. Teasdale G, Jennett B. Assessment of coma and impaired consciousness. A practical scale. Lancet 1974;2:81-4.

10. Perel P, Edwards P, Wentz R, et al. Systematic review of prognostic models in traumatic brain injury. BMC Med Inform Decis Mak 2006;6:38.

11. Turgeon AF, Lauzier F, Burns KE, et al. Determination of neurologic prognosis and clinical decision making in adult patients with severe traumatic brain injury: a survey of Canadian intensivists, neurosurgeons, and neurologists. Crit Care Med 2013;41:1086-93.

12. Côte N, Turgeon AF, Lauzier F, et al. Factors associated with the withdrawal of life-sustaining therapies in patients with severe traumatic brain injury: a multicenter cohort study. Neurocrit Care 2013;18:154-60.

13. Guyatt GH, Oxman AD, Schunemann HJ, et al. GRADE guidelines: a new series of articles in the Fournal of Clinical Epidemiology. 7 Clin Epidemiol 2011;64:380-2.

14. Papa L, Robinson G, Oli M, et al. Use of biomarkers for diagnosis and management of traumatic brain injury patients. Expert Opin Med Diagn 2008;2:937-45.

15. Zitnay GA, Zitnay KM, Povlishock JT, et al. Traumatic brain injury research priorities: The conemaugh international brain injury symposium. 7 Neurotrauma 2008;25:1135-52.

16. Skogseid IM, Nordby HK, Urdal P, et al. Increased serum creatine kinase BB and neuron specific enolase following head injury indicates brain damage. Acta Neurochir (Wien) 1992;115:106-11.

17. Shinozaki K, Oda S, Sadahiro T, et al. S-100B and neuron-specific enolase as predictors of neurological outcome in patients after cardiac arrest and return of spontaneous circulation: a systematic review. Crit Care 2009;13:R121.

18. Cheng F, Yuan Q, Yang J, et al. The prognostic value of serum neuron-specific enolase in traumatic brain injury: systematic review and meta-analysis. PLoS One 2014;9:e106680.

19. Higgins J, Green S, editors. Cochrane handbook for systematic reviews of interventions. Hoboken: John Wiley \& Sons; 2009. Available: www.cochrane -handbook.org (accessed 2016 Jan. 10).

20. Moher D, Liberati A, Tetzlaff J, et al. Preferred reporting items for systematic reviews and meta-analyses: the PRISMA statement. BMF 2009;339:b2535.

21. Wilczynski NL, Haynes RB. Optimal search strategies for detecting clinically sound prognostic studies in Embase: an analytic survey. 7 Am Med Inform Assoc 2005;12:481-5

22. Wilczynski NL, Haynes RB, Eady A, et al. Developing optimal search strategies for detecting clinically sound prognostic studies in MEDLINE: an analytic survey. BMC Med 2004;2:23.

23. Jennett B, Snoek J, Bond MR, et al. Disability after severe head injury: observations on the use of the Glasgow Outcome Scale. 7 Neurol Neurosurg Psychiatry 1981;44:285-93.

24. van Engelen BG, Lamers KJ, Gabreels FJ, et al. Age-related changes of neuron-specific enolase, S-100 protein, and myelin basic protein concentrations in cerebrospinal fluid. Clin Chem 1992;38:813-6.

25. Whiting PF, Rutjes AW, Westwood ME, et al. QUADAS-2: a revised tool for the quality assessment of diagnostic accuracy studies. Ann Intern Med 2011;155:529-36.

26. Mercier E, Boutin A, Lauzier F, et al. Predictive value of S-100beta protein for prognosis in patients with moderate and severe traumatic brain injury: systematic review and meta-analysis. BM7 2013;346:f1757.

27. Sogut O, Guloglu C, Orak M, et al. Trauma scores and neuron-specific enolase, cytokine and C-reactive protein levels as predictors of mortality in patients with blunt head trauma. 7 Int Med Res 2010;38:1708-20.

28. Higgins JPT, Thompson SG, Deeks JJ, et al. Measuring inconsistency in meta-analyses. BM7 2003;327:557-60.

29. Guyatt G, Oxman AD, Akl EA, et al. GRADE guidelines: 1. IntroductionGRADE evidence profiles and summary of findings tables. 7 Clin Epidemiol 2011;64:383-94

30. Al Nimer F, Thelin E, Nystrom H, et al. Comparative assessment of the prognostic value of biomarkers in traumatic brain injury reveals an independent role for serum levels of neurofilament light. PLoS One 2015;10:e132177.

31. Baker AJ, Rhind SG, Morrison LJ, et al. Resuscitation with hypertonic salinedextran reduces serum biomarker levels and correlates with outcome in severe traumatic brain injury patients. 7 Neurotrauma 2009;26:1227-40.

32. Böhmer AE, Oses JP, Schmidt AP, et al. Neuron-specific enolase, S100B, and glial fibrillary acidic protein levels as outcome predictors in patients with severe traumatic brain injury. Neurosurgery 2011;68:1624-30.

33. Chabok SY, Moghadam AD, Saneei Z, et al. Neuron-specific enolase and S100BB as outcome predictors in severe diffuse axonal injury. 7 Trauma Acute Care Surg 2012;72:1654-7.

34. Dauberschmidt R, Marangos PJ, Zinsmeyer J. Severe head trauma and the changes of concentration of neuron-specific enolase in plasma and in cerebrospinal fluid. Clin Chim Acta 1983;131:165-70.

35. Di Battista AP, Buonora JE, Rhind SG, et al. Blood biomarkers in moderateto-severe traumatic brain injury: potential utility of a multi-marker approach in characterizing outcome. Front Neurol 2015;6:110.

36. Gatson JW, Warren V, Abdelfattah K, et al. Detection of beta-amyloid oligomers as a predictor of neurological outcome after brain injury. 7 Neurosurg 2013;118:1336-42.
37. Gradisek P, Osredkar J, Korsic M, et al. Multiple indicators model of longterm mortality in traumatic brain injury. Brain Inj 2012;26:1472-81.

38. Guan W, Yang YL, Xia WM, et al. Significance of serum neuron-specific enolase in patients with acute traumatic brain injury. Chin 7 Traumatol 2003;6:218-21.

39. Kuroiwa T, Tanabe H, Takatsuka H, et al. Significance of serum neuronspecific enolase levels after head injury [article in Japanese]. No Shinkei Geka 1993;21:1021-4

40. Li N, Shen JK, Zhao WG, et al. S-100B and neuron specific enolase in outcome prediction of severe head injury. Chin 7 Traumatol 2004;7:156-8.

41. Luo CW, Lu MH, Bi XJ. Changes of neurospecific enolase in serum of patients with acute head injury. Chin 7 Clin Rehabil 2005;9:92-4.

42. McKeating EG, Andrews PJD, Mascia L. Relationship of neuron specific enolase and protein S-100 concentrations in systemic and jugular venous serum to injury severity and outcome after traumatic brain injury. Acta Neurochir Suppl 1998;71(Suppl 1):117-9.

43. Meissner W, Fritz H, Deufel T, et al. S-100 protein: a marker for severity of head injury. Crit Care Med 1998;26(Suppl 1):83A.

44. Meric E, Gunduz A, Turedi S, et al. The prognostic value of neuron-specific enolase in head trauma patients. 7 Emerg Med 2010;38:297-301.

45. Olivecrona M, Rodling-Wahlstrom M, Naredi S, et al. S-100B and neuron specific enolase are poor outcome predictors in severe traumatic brain injury treated by an intracranial pressure targeted therapy. 7 Neurol Neurosurg Psychiatry 2009;80:1241-7

46. Persson L, Hardemark HG, Gustafsson J, et al. S-100 protein and neuronspecific enolase in cerebrospinal fluid and serum: markers of cell damage in human central nervous system. Stroke 1987;18:911-8.

47. Pleines UE, Morganti-Kossmann MC, Rancan M, et al. S-100 beta reflects the extent of injury and outcome, whereas neuronal specific enolase is a better indicator of neuroinflammation in patients with severe traumatic brain injury. 7 Neurotrauma 2001;18:491-8.

48. Raabe A, Grolms C, Keller M, et al. Correlation of computed tomography findings and serum brain damage markers following severe head injury. Acta Neurochir (Wien) 1998;140:787-91.

49. Raabe A, Grolms C, Seifert V. Serum markers of brain damage and outcome prediction in patients after severe head injury. Br 7 Neurosurg 1999;13:56-9.

50. Ross SA, Cunningham RT, Johnston CF, et al. Neuron-specific enolase as an aid to outcome prediction in head injury. Br 7 Neurosurg 1996;10:471-6.

51. Sawauchi S, Taya K, Murakami S, et al. Serum S-100B protein and neuronspecific enolase after traumatic brain injury [article in Japanese]. No Shinkei Geka 2005;33:1073-80.

52. Stein DM, Lindell AL, Murdock KR, et al. Use of serum biomarkers to predict cerebral hypoxia after severe traumatic brain injury. 7 Neurotrauma 2012;29:1140-9

53. Vos PE, Lamers KJB, Hendriks JCM, et al. Glial and neuronal proteins in serum predict outcome after severe traumatic brain injury. Neurology 2004; 62:1303-10

54. Wang XH, Zhang XD. Evaluating the prognosis and degree of brain injury by combined S-100 protein and neuron specific enolase determination. Neural Regen Res 2006;1:649-52.

55. Woertgen C, Rothoerl RD, Holzschuh M, et al. Comparison of serial S-100 and NSE serum measurements after severe head injury. Acta Neurochir (Wien) 1997;139:1161-4

56. Yamazaki Y, Yada K, Morii S, et al. Diagnostic significance of serum neuronspecific enolase and myelin basic protein assay in patients with acute head injury. Surg Neurol 1995;43:267-70.

57. Yan EB, Satgunaseelan L, Paul E, et al. Post-traumatic hypoxia is associated with prolonged cerebral cytokine production, higher serum biomarker levels, and poor outcome in patients with severe traumatic brain injury. 7 Neurotrauma 2014;31:618-29.

58. Zhan S, Li N, Cai Y, et al. Correlation of neuron specific enolase serum concentration and prognosis in patients with severe head injury. Chin 7 Clin Rebabil $2003 ; 7: 312-3$

59. Zhang ZY, Zhang LX, Dong XQ, et al. Comparison of the performances of copeptin and multiple biomarkers in long-term prognosis of severe traumatic brain injury. Peptides 2014;60:13-7.

60. Anand N, Stead LG. Neuron-specific enolase as a marker for acute ischemic stroke: a systematic review. Cerebrovasc Dis 2005;20:213-9.

61. Ergün R, Bostanci U, Akdemir G, et al. Prognostic value of serum neuronspecific enolase levels after head injury. Neurol Res 1998;20:418-20.

62. Guzel A, Er U, Tatli M, et al. Serum neuron-specific enolase as a predictor of short-term outcome and its correlation with Glasgow Coma Scale in traumatic brain injury. Neurosurg Rev 2008;31:439-44.

63. Honda M, Tsuruta R, Kaneko T, et al. Serum glial fibrillary acidic protein is a highly specific biomarker for traumatic brain injury in humans compared with S-100B and neuron-specific enolase. 7 Trauma 2010;69:104-9.

64. Harding M, McAllister J, Hulks G, et al. Neurone specific enolase (NSE) in small cell lung cancer: A tumour marker of prognostic significance? Br 7 Cancer 1990;61:605-7.

65. Karnak D, Beder S, Kayacan O, et al. Neuron-specific enolase and lung cancer. Am 7 Clin Oncol 2005;28:586-90.

66. Filella X, Cases A, Molina R, et al. Tumor markers in patients with chronic renal failure. Int 7 Biol Markers 1990;5:85-8. 
67. Ramont L, Thoannes H, Volondat A, et al. Effects of hemolysis and storage condition on neuron-specific enolase (NSE) in cerebrospinal fluid and serum: implications in clinical practice. Clin Chem Lab Med 2005;43:1215-7.

68. Marangos PJ, Campbell IC, Schmechel DE, et al. Blood platelets contain a neuron-specific enolase subunit. 7 Neurochem 1980;34:1254-8.

69. Lima JE, Takayanagui OM, Garcia LV, et al. Use of neuron-specific enolase for assessing the severity and outcome in patients with neurological disorders. Braz 7 Med Biol Res 2004;37:19-26.

70. Casmiro M, Maitan S, De Pasquale F, et al. Cerebrospinal fluid and serum neuron-specific enolase concentrations in a normal population. Eur 7 Neurol 2005;12:369-74.

Competing interests: Eric Mercier was supported by a researchtraining grant from the Fonds de recherche du Québec - Santé (FRQS) during the conduct of the study. François Lauzier, François Lamontagne and Patrick Archambault received Clinician-Scientist Awards from FRQS. Alexis Turgeon and François Lauzier are supported by the Traumatology Research Consortium of the FRQS. Amélie Boutin has received a Doctoral Research Award (Doctoral Award - Frederick Banting and Charles Best Canada Graduate Scholarships) from the Canadian Institutes of Health Research (CIHR). Lynne Moore, Lauralyn McIntyre, Alexis Turgeon and Ryan Zarychanski have received New Investigator Awards from CIHR. France Légaré is supported by a Canada Research Chair in implementation of Shared Decision Making in Primary Care. The authors have no conflicts of interest to declare.

Affiliations: Centre de recherche du CHU de Québec - Université Laval (Mercier, Boutin, Shemilt, Lauzier, Moore, Archambault, Légaré, Turgeon), Population Health and Optimal Health Practices Research Unit; Department of Social and Preventive Medicine (Boutin, Moore); Department of Anesthesiology and Critical Care Medicine (Lauzier, Archam- bault, Turgeon), Division of Critical Care Medicine; Department of Family Medicine and Emergency Medicine (Archambault, Légaré), Faculty of Medicine (Lauzier); Department of Molecular Biology (Rousseau, Nadeau), Medical Biochemistry and Pathology, Université Laval, Québec City, Que.; Department of Haematology and Medical Oncology (Zarychanski), University of Manitoba, Winnipeg, Man.; Center for Transfusion and Critical Care Research (Fergusson, McIntyre, Turgeon), Clinical Epidemiology Unit, Ottawa Health Research Institute, University of Ottawa; Department of Critical Care Medicine (Fergusson, McIntyre), Ottawa Hospital, University of Ottawa, Ottawa, Ont.; Centre de Recherche Étienne Lebel (Lamontagne), Centre Hospitalier Universitaire de Sherbrooke, Sherbrooke, Que.; Department of Medicine (Lamontagne), Université de Sherbrooke, Sherbrooke, Que.

Contributors: Eric Mercier, Amélie Boutin, François Lauzier, Ryan Zarychanski, Dean Fergusson, Lynne Moore, Lauralyn McIntyre, Patrick Archambault, France Légaré, François Rousseau, François Lamontage, Linda Nadeau and Alexis Turgeon contributed substantially to the conception and design of the manuscript. Eric Mercier, Amélie Boutin, Michèle Shemilt and Alexis Turgeon acquired the data. All of the authors contributed substantially to analysis and interpretation of the data, either drafted the article or revised it critically for important intellectual content, gave final approval of the version to be published and agreed to act as guarantors of the work.

Acknowledgement: The authors thank Jean-François Simard for his help with obtaining the data.

Supplemental information: For reviewer comments and the original submission of this manuscript, please see www.cmajopen.ca/content/4/3/ E371/suppl/DC1 